Malaysian Journal of Social Sciences and Humanities (MJSSH)

Volume 4, Issue 8, December 2019

e-ISSN : 2504-8562

Journal home page:

www.msocialsciences.com

\title{
The Development of Friendship Instrument in Chemistry and Engagement of School of Quantitative Sciences in Universiti Utara Malaysia (UUM) Students
}

\author{
Nurul Izzati Binti Hasnun1, Nurul Aziera Binti Zainol Abidin', Nurhana Binti Roslan1, Mohamad \\ Shukri Bin Abdul Hamid1, \\ 1Universiti Utara Malaysia (UUM)
}

Correspondence: Nurhana Binti Roslan (hanaroslan1996@gmail.com)

\begin{abstract}
Friendship is a topic that should be emphasized and studied, and it can be positive or negative. There are many forms of friendship that can be termed, but it may also differ from one's perspective and certain characteristics of a person. The value of friendship is very important to study in order to know the level of our friendships. In college student development, peer influence can also influence student engagement in engaging in their college activities. It can be seen in terms of involvement in sports activities, curriculum activities and more. The main purpose of this study was to develop of Friendship instrument in chemistry and engagement of SQS UUM students and find the relationships between genders with chemistry and engagement. Using Factor Analysis in order to develop valid and reliable of the friendship Instrument based on chemistry and engagement. In order to study the validity of the data, face validity was used before the instrument was distributed in which the pilot study was conducted. To determine which factor is best, the analysis uses varimax rotation and selects which component is best and meets the criteria. Normality test was used to find the data was normal or nonnormal. Spearman Correlation and Chi Square Test method used in the non-normal data to find the relationship of selected variables.
\end{abstract}

Keywords: friendship, psychometric, factor analysis, spearman correlation, chi square test

\section{Introduction}

In today's world, we can see that friendship is a bond of love between people and it can be the friendship between family, and friends. Friendship is a topic that should be emphasized and studied and it can be positive or negative. It is widely studied in academic fields such as social psychology, sociology, communication, philosophy and anthropology. There are many forms of friendship that can be termed, but it may also differ from one's perspective and certain characteristics of a person. These qualities include, kindness shown, one's loyalty, sympathy, honesty with one another, generosity, compassion and love. When we talk about friendship, it's a well-maintained relationship where we always give priority to our friends when they have a problem. Friendship can also influence someone to shape ourselves for the future. The value of friendship is very important to study in order to know the level of our friendships.

Friendship is an important term in the lives of people in the world. According to an article from Shushok (2008), he found that philosophers Aristotle and Cicero have argued that friendship is an important aspect of human development in the world. In today's teenage age, modern scholars have 
pointed out that friendship in a peer group plays an important role (Astin, 1993b). Personal growth and development can be influenced by peer groups and is the most powerful influence on their lives. However, there are disagreements about the formation of friendships as some raise the issue of whether friendship is a matter of critical scholar interest (Allan, 1989). As we know with friendship, it can influence a person to be someone good or bad. Some are influenced by negative attitudes and some are influenced by positive attitudes. This is in line with the kind of friends we meet as we grow up.

In college student development, peer influence can also influence student engagement in engaging in their college activities. It can be seen in terms of involvement in sports activities, curriculum activities and more. Friendship is also an integral part of the development of individuals who are growing up today. In addition, scholars have found that peer pressure on young people today will also influence social growth and academic performance in pre-adolescence. Involvement in college activities is very important to enhance one's skills and qualities. So, it is very important to build good friendships in building friendships. It can also be seen whether a person engaging in the activity is influenced by friendship or whether it is not related to the term friendship.

Some people think that if their friends are not participating in the program they want to join, they will feel ashamed to be present and it will hinder their interest in engaging them in any activity. Friendship is also an important based on academic point of view. This is because we can see how friendships can help someone to improve their understanding by talking to each other. Friendship also has a positive effect on a person's academics as it can create a harmonious atmosphere and motivate their friends if they are experiencing stress while learning. It can also be negative where our mood changes if we have a problem with our best friend and maybe the effect will be more negative as it is stressful.

\section{Background of study}

Friendships are just like other relationships in this world. The quality of friendship is hard to judge in terms of behavioral. Individuals can identify and distinguish regarding what types of friendships they are involved in such between close friends, casual friends and acquaintances. These differences of friendships' types are obvious criterion to measure the quality. Also, gender differences that exist in any friendship provides a criterion to validate the measurement of friendship this is because there is enough evidence saying that the differences in gender developed in friendship do exist. According to Bell, 1991; Jones, 1991; Sapadin, 1988; Wright \& Scanlon, 1991, Friendships that developed among the women can be characterized as better in terms of quality, closeness, enjoyment, intimacy and nurturance. Hence, any measurement towards friendship must be sensitive enough so that the friendship developed among women and men can be differentiate (Mendelson, M. J. \& Aboud, F. . (2014).

Next, in todays' life in this world, there will be friendships that exist in the engagement of the individuals in terms of his or her activities spent, connections made between friends in university life or working life. According to Alexander W. Astin (1993), the most important of influence based on growth and development during the undergraduate years in the university is the student's peer group. The development of an individual also depends on how he or she interacts with friends. Based on Astin 1984, the students who involved in academic and extracurricular activities tend to have a better chance to success compared to the individuals who are not. Next, according to Hu and Kuh (2002), student learning and personal development during college is the most important factor for student engagement.

According to Crosnoe, Cavanaugh, and Elder, Jr. (2003), there is evidence saying that the friends influenced positively towards the academic performance. This can be proved by the analysis made using the longitudinal data regarding health issues among the adolescence and the result showed that the students who had friends who enjoyed school tended to perform better than their peers who had friends who did not enjoy or accomplish particularly well academically. The two common measures to indicate how a student succeeds in college are basically based on engagement and achievement of an individual. One of the problems emerged in this study is there is an insight regarding how friendship do influence the engagement and achievement of an individual. It is undeniable that friendship impacting 
on the way people deal and interact with one another. Also, towards assigning reasons for the individuals' own behaviour and for the others' behaviour. (Mauk, A.J., 2011).

\section{Problem statement}

Previous researches regarding the study of friendship had been conducted but there is still some limitations found in the research such as focus on the target sample of population is not sufficient enough to obtain the exact result, instrument construction that is limited only towards engagement of students in the activities, anonymous nature of the survey and demographics of the respondents that where it results in the over representative in women respondents for instance. Hence, in this study there is a need and effort to conduct the appropriate instrument regarding Friendship study in assessing every details of Friendship's role towards the chemistry, engagement and achievement of the students in the university. Hence, this study intends to construct a validity and reliability of Friendship instrument for examining the chemistry developed among friends, engagement of the students towards the activities and achievement of the students in academic performance and how these items relate with a friendship.

\section{Purpose of this study}

The purpose of this study was to study the role of friendship among School of Quantitative Science (SQS) students in terms of their experiences by developing the validity and reliability of friendship instrument for chemistry, engagement and achievement of the students using factor analysis. This study also explores how friendship among college students is. Does it bring good results in friendship or does it make a bad impression on a person. This study examines the extent to which students are engaged in college activities and their academic achievement while in college. Friendships can be seen in many ways. Some report that this type of friendship is caused by the duration of their introduction. In addition, the period of recognition plays an important role in establishing trust in others. This study also assesses the various aspects of student friendship by measuring the friendships that exist among SQS students. The nature and quality of the friendship began to be studied to predict the possible relationship between engagement and achievement.

\section{Objectives of the study}

In this study, the objectives are developed and achieved through:

i. To develop valid and reliable of the Friendship Instrument for chemistry and engagement for SQS, UUM students.

ii. To evaluate the Friendship in chemistry and engagement of students by using the Factor Analysis to develop instrument.

iii. To investigate the relationship between level of friendship and all factors get in Factor Rotation.

iv. To know the relationship between difference gender in their chemistry and engagement in college.

\section{Significance of study}

This study seeks to explore in advance towards the field of the friendship that relates to its knowledge and theory. Also, how the friendship impacts the university student outcomes. Based on, friendship do influence an individual based on his or her involvement towards activities, academic progress and the success achieved by the student while in the university. This study provides proof that friendship is an important component of university students' development based on examining the influence that friendships have on engagement and achievement. Besides, this study is important for university administrators and educators especially lecturers to help the students achieve successfully in the university this is because, university faculty and staff can create conditions that encourage the student 
success by understanding the various components that consist in friendship. The interpersonal relationship development of an individual in university can be improved through understanding the findings of this study. Also, the engagement and success of a student or and individual due to their friendship should be a significant factor in an educational setting.

\section{Methodology}

According to Igwenagu, (2016), methodology can be described as the systematic and theoretical analysis of the methods that applied towards a field of study. It consists of the body of methods of the theoretical analysis and the principles that relates with a branch of knowledge. In methodology, it includes the concepts like paradigm, theoretical analysis, phases and quantitative or qualitative technique (Igwenagu, 2016). A methodology offers the theoretical base for understanding and proposing the best methods or practices to be applied towards a specific case such as calculate a specific result (Igwenagu, 2016). Hence, in this study the role of friendship developed among the university students in terms of their experience towards friendship regarding the level of friendship, chemistry with friends and achievement and engagement of students in the university are analyzed. This study also described the nature of friendship and gender difference developed in the friendship among university students, then analyzed how does gender difference in friendship give impacts towards student engagement in university activities and lastly investigated how it influences the performance of the university students in academic achievement.

\section{Development of instrument}

\section{The development of construct items}

The internet survey using the Google Form was conducted to gather the required data to study and analyze the role of friendship among School of Quantitative Science (SQS) students in terms of their experiences, gender differences existed in the friendship and how the friendship impacts the students' engagement and achievement in their academic life. The internet survey was conducted among the SQS students specifically in UUM. An effective method to conduct and connect with such large groups of respondents and provide the chance to collect large amounts of data is through internet surveys.

Moreover, internet surveys nowadays are considered as significant components in today's world which is known as contemporary and computerized society which already substituted the old-fashioned method that use the pen or paper survey to gather data. (Mauk, A.J., 2011). The Friendship Instrument were constructed and consisted of the four parts of interest to develop the validity and reliability of friendship instrument for chemistry, engagement and achievement among the students using factor analysis. In this survey, there are 4 sections that been proposed which consists of 52 items. The 52 items of questions were considered and implemented in the survey in attempt to construct the friendship instrument for chemistry, engagement and achievement of the students.

The first part is Section A which consists of the basic profile information about the respondent which this section interested to identify the age, gender, race, description of the respondent based on outgoing, introvert and in between and most preference of the respondent towards having a few close friends at a time or having a lot of friends around the respondent. Next, second part is Section B that consists of level of friendship which refers to how far you treat or appreciate your friends. Then, the third part, Section C consists of chemistry with your friends which are the questions involved the emotional and psychological interaction between the respondents and their friends.

The last part refers to Section D consists of achievement and engagement of students which in this part the researcher wants to look for the influence or impact of friendship towards the students' engagement in activities they be involved in university and the students' achievement in their academic performance in the university. The semantic differentiate scale is employed in this study to ask the respondents to give their own rate based on the types of questions they answered which this survey 
type is the most reliable way to get information based on the respondents' emotional attitude towards the topic of interest. Hence, this scale and rate used in this study can be easily and correctly understand by the respondents to answer which makes the information collected very reliable. All the sections developed with the 52 items in the questionnaire can be referred to Figure 1 below.

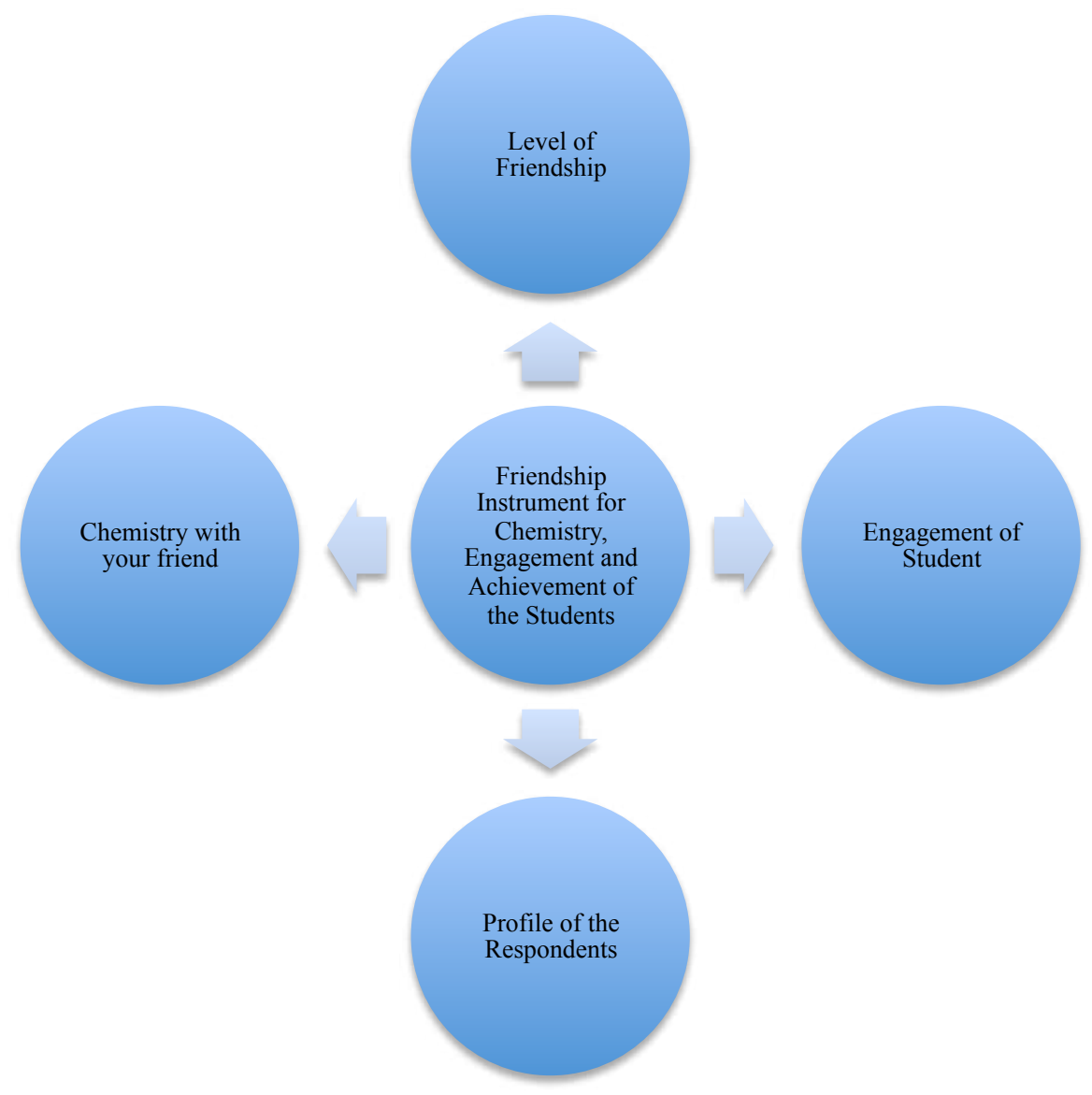

Figure 1. Four sections that consists of friendship instrument for chemistry and engagement of the students

Friendship Instrument for Chemistry, and Engagement of the Students

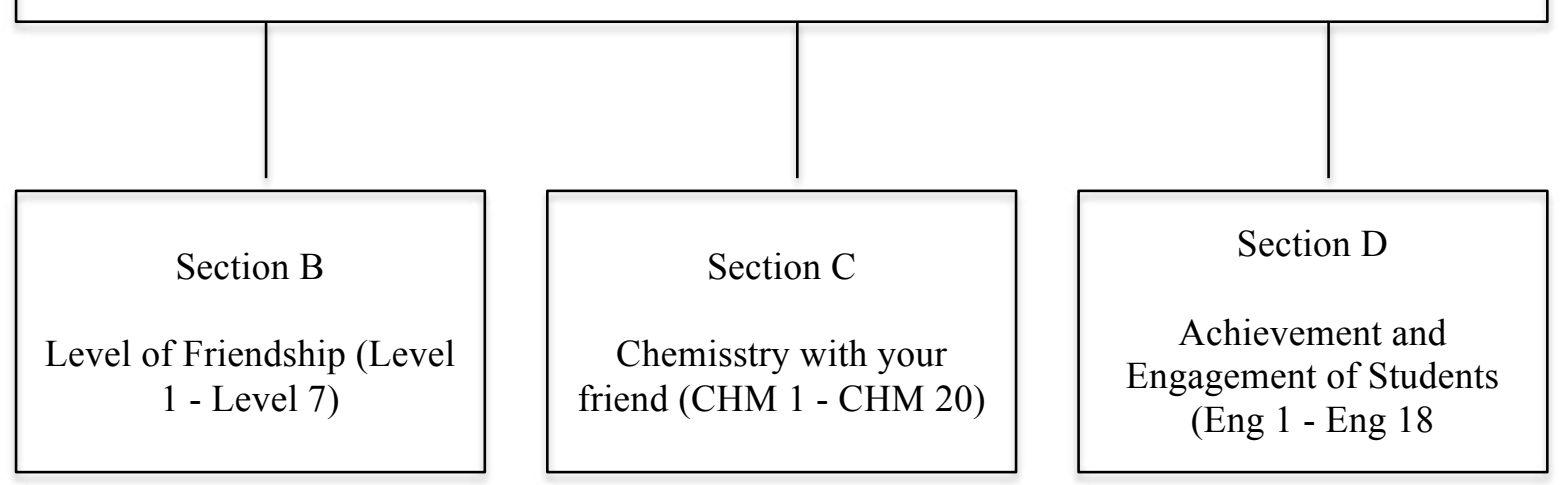

Figure 1. Flow chart of Friendship instrument for chemistry, engagement and achievement of the students 
Based on the figure above, there are three sections of interest that involved in attempt to construct the 47 items of questions regarding the friendship instrument for chemistry, engagement and achievement of the students. The instrument consists of Section B, Section C and Section D which refers to Level of Friendship, Chemistry with your friend and Achievement and Engagement of students respectively. In Section B, the questions are mainly about level of friendship which consists of LVL 1 to LVL 7 questions. LVL 1 refers to rate given to friends based on not all importance to very importance.

Next, LVL 2 refers to priority between friends or boyfriends. Then, LVL 3 question is regarding which type of person you are. LVL 4 question is about what you will do if your friend has done something wrong while LVL 5 question is regarding what you will do if your friend is nervous to jump into river when going to a vacation. Next, question of LVL 6 is about what you will do if your friend been insulted in public. Lastly, in LVL 7 of question is about what you will do if your friend is late to a party and the food is about to be over. All this questions that consists in Section B which based on Level of Friendship are conducted and provided with multi choice of answers.

Next, in Section C that consists of questions regarding chemistry with your friend, the questions are constructed based on the chemistry that being developed among the respondents and their friends. The questions in this section are based on CHM 1 to CHM 20. The questions are answered using semantic differential scale which is strongly disagree to strongly agree. The questions developed in CHM1 to CHM 2 are mainly regarding chemistry among friends. CHM 1 refers to 'I feel like my friend really understands me'. CHM 2 refers to 'I feel I can tell my friend anything'. CHM 3 refers to 'I feel like I really understand my friend. CHM 4 refers to 'My friend feels like he or she can tell me everything'. CHM 5 refers to 'the communication between my friend and I is easy and effortless'. CHM 6 refers to 'My friend feels that he or she can trust me'. CHM 7 refers to 'I feel like I can trust my friend'. CHM 8 refers to 'My friend finds me funny and interesting'. CHM 9 refers to 'I find my friend funny and interesting'.

Next, CHM 10 refers to 'My friend and I find the same things funny'. CHM 11 question refers to 'I feel good when I am around my friend'. CHM 12 question refers to 'I get excited to talk to or see my friend'. CHM 13 question refers to 'My friend and I share the same interests'. CHM 14 question refers to 'I care about the general well-being of other people'. CHM 15 question refers to 'My friend is a warm and caring person'. CHM 16 question refers to 'My friend cares about the general well-being of other people'. CHM 17 question refers to 'I like my friend because he or she likes me'. CHM 18 question refers to 'My friend and I have similar morals'. CHM 19 question refers to 'My friend and I have the same life goals'. Last question of CHM20 is about 'My friend and I have a similar level of education'.

The last part of questions consists in Section D are about Achievement and Engagement of students. This section applied the semantic differential scale based on never to always. The questions regarding the engagement of students are based on ENG 1 - ENG 18 while the questions about achievement of students are based on ACH $1-\mathrm{ACH} 2$. The question that consists in ENG 1 to ENG 18 is based on these questions respectively. Basically, questions from ENG 1 until ENG 18 are based on the engagement of the respondents in class which is ENG 1 refers to asking questions in class or contributing towards group discussion. Next, ENG 2 refers to coming to class without completing the assignments. Then ENG 3 refers to working with other students on projects during class. ENG 4 refers to working with classmate outside of class to prepare for assignments. ENG 5 refers to participating in a community-based project as part of a regular course. ENG 6 refers to talking about career plans with a faculty member or adviser. ENG 7 is based on discussing ideas from your readings or classes with faculty members outside of class. ENG 8 refers to discussing ideas from your readings or classes with others outside of class such as students, family members and co-workers. ENG 9 refers to attending a meeting of club or organization in campus.

ENG 10 refers to working on a campus committee, student organization or project in campus. ENG 11 refers to working on off-campus committee, organization or project such as community event. ENG 12 refers to managing or providing leadership for a club or organization on or off the campus. ENG 13 refers to attending a talk. ENG 14 refers to make use of campus facilities such as Sport Centre and 
others. ENG 15 refers to playing a team sport. ENG 16 refers to participating in activities to improve the spiritually like prayers. ENG 17 refers to trying to have a better understanding regarding someone else's perspective. ENG 18 refers to learning something that change the way you understand an issue or concept. ENG 19 refers to the student's recent cumulative CGPA for this academic year. Lastly, ENG 20 refers to student's expected cumulative GPA for this academic year.

\section{Measurement scale}

The Friendship instrument was constructing based on the 52 items. The instrument measures the validity and reliability of friendship for chemistry and engagement of student. In attempt to develop the instrument, factor analysis is applied in this study to evaluate the friendship study. All the 52 constructed items that consists within each section which are section A, B, C and D respectively were measured and examined at the individual level. Semantic Differential scale and Multiple-Choice Answers were employed in the questionnaire. The scale ranged from not at all importance to very importance in section B. Next, in section C comprises of range that starts from 1 which identified as strongly disagree to number 5 as strongly agree. Moreover, in section D consists of scale ranged from never to always where scale 1 known as never while scale 5 is identified as always. The result obtained for the mean score were applied and categorized into five level of importance based on friendship.

Table Mean score of Level of importance based on friendship

\begin{tabular}{clc} 
No. & Level of importance based on friendship & Mean Score \\
\hline 1. & Not at all importance & $1.00-1.79$ \\
2. & Slightly not importance & $1.80-2.59$ \\
3. & Importance & $2.60-3.39$ \\
4. & Slightly importance & $3.40-4.19$ \\
5. & Very importance & $4.20-5.00$ \\
\hline
\end{tabular}

Table Mean score of Level of agreement regarding friendship

\begin{tabular}{clc} 
No. & Level of agreement about friendship & Mean Score \\
\hline 1. & Strongly Disagree & $1.00-1.79$ \\
2. & Disagree & $1.80-2.59$ \\
3. & Neither agree or disagree & $2.60-3.39$ \\
4. & Agree & $3.40-4.19$ \\
5. & Strongly agree & $4.20-5.00$ \\
\hline
\end{tabular}

Table Mean score of Frequency of level participation or involvement of the students towards the activities

\begin{tabular}{clc}
\hline No. & $\begin{array}{c}\text { Frequency of level participation or involvement } \\
\text { of the student towards the activities }\end{array}$ & Mean Score \\
\hline 1. & Never & $1.00-1.79$ \\
2. & Rarely & $1.80-2.59$ \\
3. & Sometimes & $2.60-3.39$ \\
\hline
\end{tabular}



4. Often
$3.40-4.19$
5. Always
$4.20-5.00$

\section{Validity Process}

To check for validity process throughout this study, three methods of validity test was employed which refers to content validity, face validity and pilot study. The content validity was carried out during the new instrument is being developed. In attempt to ensure that a new survey friendship instrument includes all the items that are essential and eliminates all the desirable items to a specific construct domain. Next, literature reviews and evaluation from the expert judges or panels are applied and established in this study so that items that have been developed in the questionnaire can be improved by the expert validation. Then, after the items developed in the questionnaire had been revised according to the feedback and guidance received from the expert judgment, the face validity test was done. The face validity was constructed in attempt to gain the feedback and opinion based on the questionnaire. The face validity was done by seeking approval and validation regarding the questionnaire from our psychometric lecturer.

Also, a pilot study was employed in this study in order to evaluate the feasibility and improvement towards the questionnaire before proceeding with analysis of a data. The pilot study was conducted by selecting a few students from a representative on a smaller scale based on the large survey group of the SQS students and has them to answer the questionnaire. 20 students from the SQS sample were selected to be involved in the pilot test study. The results obtained from the pilot study that comes from a small group of respondents in SQS provide us a good idea towards the questionnaire that we conduct either it is effective or not at fulfilling the goals of the overall study.

\section{Scope of the study}

The population in this study consists of all the School of Quantitative Sciences (SQS) students from Universiti Utara Malaysia (UUM). The sample size of target respondents from the population were collected and obtained among 241 students who come from 900 population of School of Quantitative Sciences in UUM.

\section{Data collection}

After the item in the instrument had been revised using the validity procedure, the pilot data collection was conducted. The questionnaires were constructed using the internet survey using through Google Form and sent to the target sample from the population that consists of undergraduate and postgraduate students from School of Quantitative Sciences (SQS) in UUM. The pilot study was employed in collecting the data. The total of pilot samples was determined by calculation conservatively of sampling size for pilot study. A total of 20 samples were included in the pilot.

\section{Data analysis}

Reliability Analysis, Factor Analysis and Descriptive Analysis. The validity and reliability of the Friendship for Chemistry and Engagement of student Instrument were constructed through conducting the survey by referring to the previous literature review, content and face validity and pilot study. The data collected in the survey was analyzed using SAS EG 7.1 (64-bit). In this study, the descriptive analysis that consists of distributions, frequencies and percentages of demographic data of the respondents were explored.

Next, the data in section B, C and D that comprises of the items rated by the respondent based on their own agreement were analyzed using the box plot and bar chart to explain regarding the overall details based on the data in section B, C and D. Also, the reliability test using Cronbach's alpha coefficient and factor analysis were employed in this study to look for the consistency of the answers answered by 
the respondent and to measure the correlation between the construct items and factors involved respectively.

In this study, reliability analysis was employed to measure the accuracy of an instrument by measuring the consistency of data whether it produce the same results if it is used in the same situation using repeated occasions. The consistency of a measure is carried out using the Cronbach's alpha. The Cronbach's alpha was conducted by Lee Cronbach during 1951 to provide a measurement regarding the internal consistency of any test or scale. It is expressed as $\mathrm{s}$ number between 0 and 1 . Internal consistency can be described as all the items in the test or scale is being measured using the same concept or construct and thus it is connected to the inter-relatedness of the items within the test.

To ensure validity, internal consistency should be determined first before conducting any test for research or examination purposes. In addition, the amount of measurement error in a test is showed based on the reliability estimation. To be simply understood, the interpretation of reliability is the correlation of test with itself (Tavakol, M., \& Dennick, R, 2011). Hence, the reliability test was conducted in this study to determine how the items in the survey were related to each other. Using the Cronbach's coefficient alpha, the closer the value of $\alpha$ coefficient to 1 , the more the items have shared the high covariance among them and number of items in the analysis.

The result of the Cronbach's Alpha in this study can be found in Table 3.4.1 and Table 3.4.2 respectively. The item reliability test to check for the consistency of the items constructed in this study and how the items in the survey were related to each other. Cronbach's Alpha for the friendship items which refers to all items in the survey shows an inter-item reliability of 0.9553 . For the level of friendship, the Cronbach's Alpha was 0 which indicates poor. Next, for the chemistry items, the Cronbach's Alpha was 0.94889 which refers as excellent in consistency while for the engagement items, the Cronbach's Alpha was 0.94889 which shows the excellent consistency exists among the items.

Also, it means that the items measure the same underlying concept. Based on Tavakol, M., \& Dennick, R. (2011), the acceptable values of alpha are in the range between of 0.70 to 0.95 . This is because, a low value of alpha could be due to a low number of questions and poor interrelatedness between the items while a highest value of alpha refers to redundancy of some items as they are testing the same question but in a different appearance. Thus, a maximum alpha value of 0.90 has been suggested (Tavakol, M., \& Dennick, R, 2011). Next, factor analysis was employed in this study to identify the dimensions of a test. According to Mauk, A.J., 2011, factor analysis is the analysis that involves a large set of measures in attempt to identify a smaller set of common elements which are known as factors (Ary, Jacobs, and Razavieh, 2002).

In this study, the factor analysis was conducted on the 39 items in the friendship measure by employing varimax rotation to verify how the data set used in this study would result in factors. The results and tables that relates to Factor Analysis in this study can be found in Table 3.5.1, Table 3.5.2, Table 3.5.3, Table 3.5.4, Table 3.5.5, Table 3.5.6, Table 3.5.7 and Table 3.5.8 respectively. According to the results of the factor analysis loads, the survey instrument shows the adequate sample of data set to perform the related testing based on the result of Kaiser-Meyer-Olkin (KMO) test. Based on the review of the eigenvalues analysis, the principle component data and the scree plot, there are 7 factors presented for chemistry and engagement of the students exists in the friendship.

Normality test. The normality test was employed in this study to determine whether the data set is well-modeled by normal distribution or not. Hence, in this study the data set from the questionnaire that has been analyzed is been tested for normality of data using the mean. The mean for each factor will be used to determine for the normality test in this study because it is easy to test the mean of all the variable for each factor in order to check for normality of the data set.

Correlation Analysis. A correlation analysis was employed in this study to determine the relationship between all the variables involved. Since the normality test for the data is not normal hence, Spearman Correlation coefficient was applied to measure the strength of the relationship between the variables. 
The Spearman Correlation coefficient is a nonparametric correlation to assess how well an arbitrary monotonic function can describe a relationship among the variables without making any assumptions about the frequency distribution of the variables. The result of spearman correlation coefficient tested among the variables to see the relationship and strength among them can be found in Table 3.7.2. The table shows the result of correlation between all the factors involved. The relationship between level of friendship and other two important variables which are chemistry and engagement of the students with their friends can be obtained based on the result of spearman correlation coefficient to determine which factor has the highest correlation.

Chi-square test. In this study, the chi-square test was employed since the data is not normally distributed. The chi-square test refers to a statistical test that measures the relationship between the two variables which are categorical. The result of this test can be found in Table 3.8.1. The chi-square test was conducted to determine and analyze the relationship of gender difference that exists in Chemistry and Engagement of the students towards their friendship. The hypothesis testing was formed to test for the significance of the relationship that exists among the gender difference and chemistry in friendship also the significance of the relationship that exists among the gender difference and engagement in friendship.

\section{Data Analysis and Finding}

\section{Demographic Frequency}

In the demographic section, data were analyzed by frequency in terms of age, gender, race, describe yourself and which do you prefer. This data was collected from the students of the School of Quantitative Science (SQS) at University Utara Malaysia where the sample was taken by randomly sampling.

Table 3.1.1 shows the overall details of the Demographic section of the questionnaires. The data were analyzed according to how much the SQS student answered about the friendship they had acquired while continuing their studies at University Utara Malaysia during their involvement in college activities, and achievements. The lowest age group in this study was $18-21$ years old and the result show only 43 students (18\%) participated in answering this question. Then, the highest frequency in age group was $22-25$ year-old which is 140 students and it about $58 \%$ student participated. So, a mostly participant that answers the question was come from student who have the age around 22 yearolds until 25 year olds. In this study, the gender distribution showed the highest frequency on Female where the percentage was $73 \%$ (177) compared to men who showed only $27 \%$ (64) who answered this question.

There are many ethnic groups in Malaysia. Table 3.1.1 shows the highest frequency coming from Malay which is $84 \%$ (202) and the lowest ethnicity is from Others which is only $0.4 \%$ (1) that answer all question. To find out what the characteristic of participant, the question about describe yourself was very helpful as it showed that most participants were "someone in between" which is $49 \%$ (118) and the lowest frequency was "introverted" which is only $16 \%$ (38). In friendship we need a lot of friends but it can also be just a small amount of friends. It follows the majority of the students themselves. In this study, the highest frequency was from "A few friend" which represented 59\% (141) and "A lot friend" only $49 \%$ (100). For achievement, mostly respondent show highest value for CGPA was around $3.00-3.66$ while the lowest value for CGPA was from $2.00-2.99$. The percentage show for CGPA $3.00-3.66$ was $68 \%$ (164) and for $2.00-2.99$ was $5 \%$. So mostly show the highest CGPA which is more than 3.00 and above and it means friendship give motivation and strength for respondent. According to the journal from Pratt (2007), he mentioned that they conducting the interview to studies about friendship, and the interview data that most provide an insight into the quality of friendship and adjustment while at the University. 
Table Mean score of Level of importance based on friendship

\begin{tabular}{|c|c|c|}
\hline \multirow[t]{2}{*}{ Category } & \multicolumn{2}{|c|}{$\begin{array}{c}\text { Area of interest } \\
\text { Friendship SQS STUDENT }\end{array}$} \\
\hline & Frequency & $\%$ \\
\hline \multicolumn{3}{|l|}{ AGE } \\
\hline $18-21$ years old & 43 & 18 \\
\hline $22-25$ years old & 140 & 58 \\
\hline$>26$ years old & 58 & 24 \\
\hline \multicolumn{3}{|l|}{ GENDER } \\
\hline Female & 177 & 73 \\
\hline Male & 64 & 27 \\
\hline \multicolumn{3}{|l|}{ RACE } \\
\hline Malay & 202 & 84 \\
\hline Chinese & 25 & 10 \\
\hline Indian & 13 & 5 \\
\hline Others & 1 & 0.4 \\
\hline \multicolumn{3}{|l|}{ Describe yourself: } \\
\hline Introverted & 38 & 16 \\
\hline Somewhere in between & 118 & 49 \\
\hline Outgoing & 85 & 35 \\
\hline \multicolumn{3}{|l|}{ Which do you prefer } \\
\hline A lot friend & 100 & \\
\hline A few friend & 141 & \\
\hline \multicolumn{3}{|l|}{ Recent CGPA } \\
\hline $2.00-2.99$ & 11 & 5 \\
\hline $3.00-3.66$ & 164 & 68 \\
\hline $3.67-4.00$ & 66 & 27 \\
\hline
\end{tabular}

\section{Analysis of Boxplot / Bar graph}

In the table 3.2.1 shows that all the item code used in this study. The analysis is based on these 3 items as part of friendships analysis. The item LVL was for Level of friendship, CHM for Chemistry of friendship, and ENG for Engagement Students.

Table Friendship Part (Referring to box plot and bar graph)

\begin{tabular}{ccl}
\hline No. & \multicolumn{1}{c}{ 3 Part of Friendship } \\
\hline & $\mathbf{1}$ & (LVL) Level of Friendship \\
$\mathbf{2}$ & (CHM) Chemistry of Friendship \\
& $\mathbf{3}$ & (ENG) Engagement Student \\
\hline
\end{tabular}

In illustrate more detail, the bar graph and boxplot were used to show what the scale respondent mostly rated in friendship. The bar graph below shows the result for Level of friendship: 


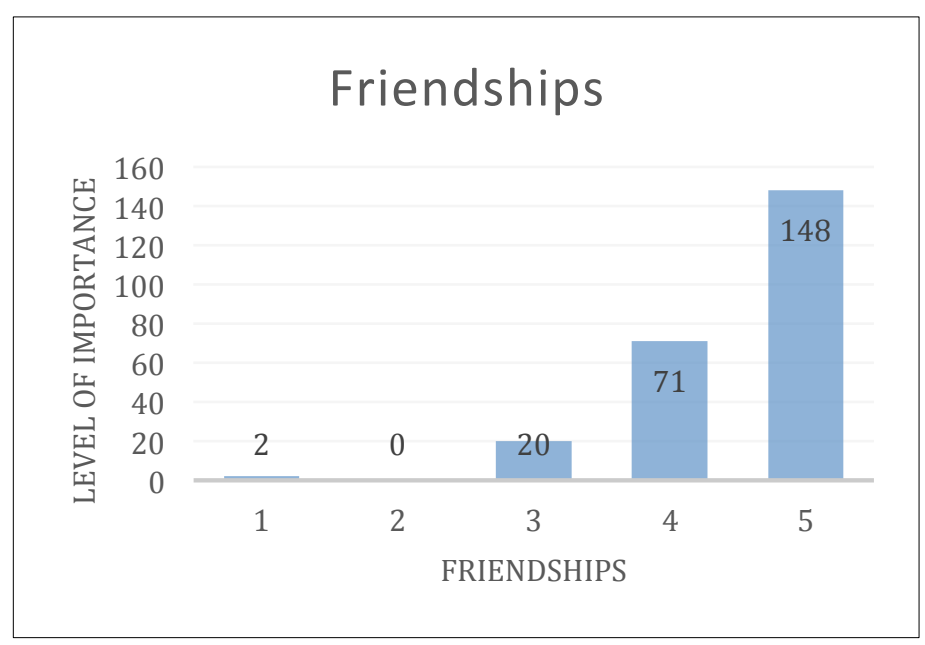

Figure . Bar Chart of Level of friendship (LVL1)

Bar chart for level of friendship showed on Figure 3.2.1. Mostly all the respondent rated the scale from 4 to 5 which can be considered as the consistent between in the questions. It also means that the level of friendship was very high among student in University Utara Malaysia. The highest number in frequency was scale 5 which means their friend was very importance in their life. Only 2 persons put the scale 1 and maybe they feel their friend is not at all importance.

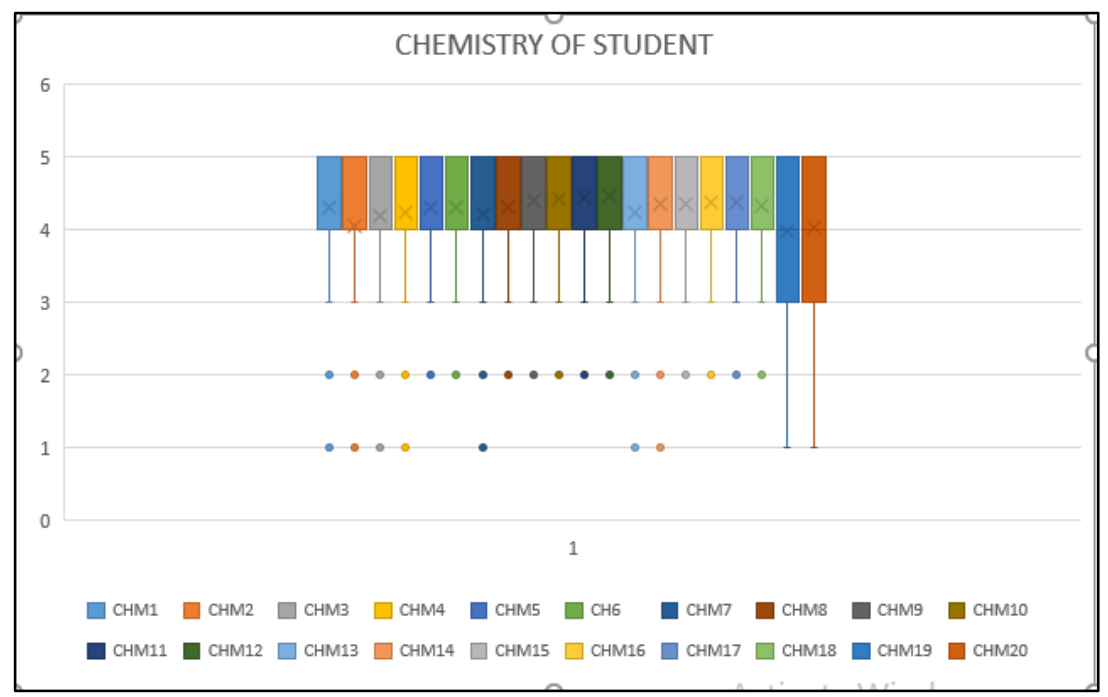

Figure $\{3.2 .2\}$ : Boxplot of Chemistry of Student

Boxplot in Figure 3.2.2 shows the combination of all the questions that was used in this study. This question mostly asks about the respondent chemistry with their friend. The result shows that all the respondents rated the scale between 4 to 5 which can be considered as consistent between the questions. But, only two results shown that respondent rated between 3 to 5 which is from CHM19 and CHM20. So, mostly said they have their chemistry with their friend while conducting this instrument. 


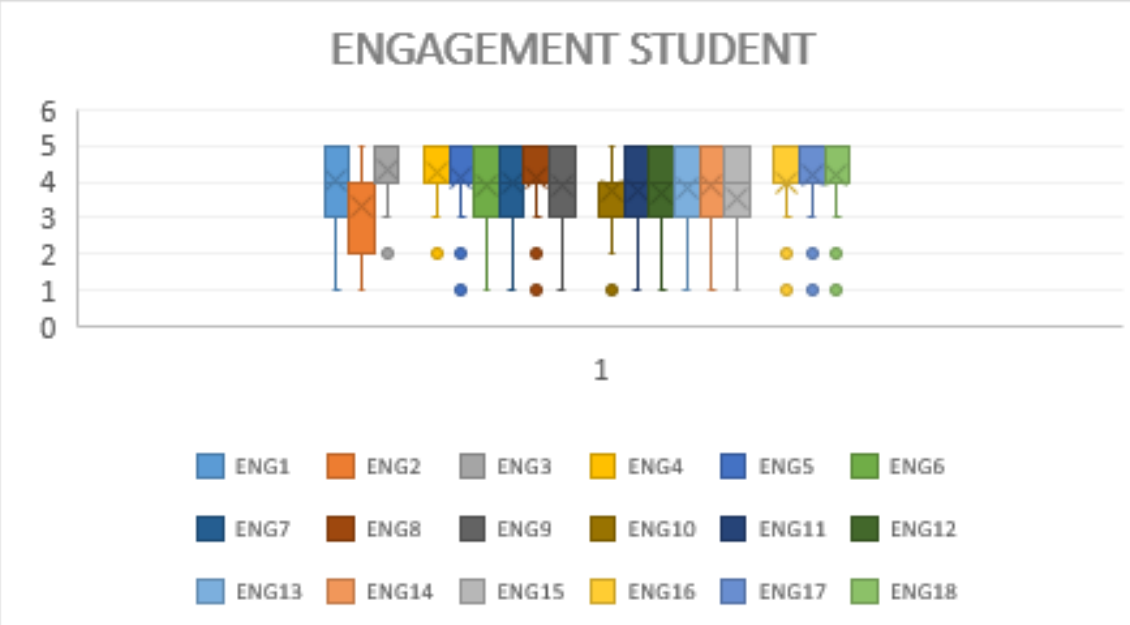

Figure \{3.2.3\}: Boxplot of Engagement student among SQS students.

In figure 3.2.3, the result show mostly rated between 3 until 5 which mean they always join the college activities and participate in other activities such as ask the question during the class and vice versa. In Figure 3.2.3, only one result show the respondent rate between 2 to 4 which is ENG2. The rest from ENG3, ENG4, ENG5, ENG8, ENG16, ENG17, and ENG18 show the respondent rate between 4 to 5 scales.

\section{Description Analysis}

The result in Table 3.3.1 is about the mean and standard deviation from the all variable follow the part of friendship list in table above. The result for the mean of the level of Friendship was 4.5062. It can describe that the respondent mostly said their friend was very importance. The Chemistry show 4.2811 for the mean and the Engagement mean was 3.9322. All the result for the 3 aspect show very highest mean in this study when we combine the question together and analysis based on different aspect that listed in the table 3.3.1. Based on this finding, mostly the SQS students were scale that their friend is importance, and they have the chemistry in their friendship.

Table $\{3.3 .1\}$ : Description Analysis for 3 parts in friendship

\begin{tabular}{rlrr}
\hline NO & 3 Aspects of friendship & Mean & $\begin{array}{c}\text { Standard } \\
\text { Deviation }\end{array}$ \\
\hline $\mathbf{1}$ & (LVL) Level Of Friendship & 4.5062 & 0.7195 \\
$\mathbf{2}$ & (CHM) Chemistry & 4.2811 & 0.7447 \\
$\mathbf{3}$ & (ENG) Engagement Students & 3.9322 & 0.9957 \\
\hline
\end{tabular}

\section{Analysis of Cronbach's Alpha Coefficient}

To determine the consistency of the items constructed in this study, Cronbach; s Coefficient Alpha was already used to determine and measure the reliability of the variables collected for each variable contained in the friendship study instrument based on chemistry and engagement. The result of reliability has shown as below:

Table 3.4.1: Cronbach Coefficient Alpha for each variable used

\section{Cronbach Coefficient Alpha}

Variables

Alpha 


\begin{tabular}{cc}
\hline Raw & 0.952006 \\
Standardized & 0.955293 \\
\hline
\end{tabular}

In order to make further analysis such as Factor Analysis, all the items in this study need to be used and it based on these 3 aspects which is LVL, CHM, and ENG. The result Cronbach's Coefficient Alpha show for overall items was 0.9553 which is it indicate high internal consistency.

Table 3.4.2: Cronbach Coefficient Alpha for 3 aspect of friendship

\begin{tabular}{rlrr}
\hline No & \multicolumn{1}{c}{ 3 Aspects of friendship } & $\begin{array}{c}\text { Standardized } \\
\text { Alpha }\end{array}$ & Consistency \\
\hline $\mathbf{1}$ & (LVL) Level Of Friendship & 0 & Poor \\
$\mathbf{2}$ & (CHM) Chemistry & 0.94889 & Excellent \\
$\mathbf{3}$ & (ENG) Engagement Students & 0.93091 & Excellent \\
\hline
\end{tabular}

In Table 3.4.2, the result show only Level of friendship not have consistency which is poor consistency for this item. The highest aspect of friendship was 0.94889 while for Engagement also show the highest value which is 0.93091 . It means the chemistry and Engagement show the high consistency in this study. The $\alpha$ ranges from 0.7 to 0.9 indicated from acceptable reliability to excellent reliability, so this study can conclude this two variable was reliability.

\section{Factor Analysis}

Table 3.5.1: Total number of records data

\begin{tabular}{lr}
\hline Input Data Type & Raw Data \\
\hline Number of Records Read & 241 \\
Number of Records Used & 241 \\
N for Significance Tests & 241 \\
\hline
\end{tabular}

From the table 3.5.1, we can see the total number of records used or the sample size in this study, $\mathrm{n}=$ 241. The value of sample size greater than 200 , then the raw data is considered acceptable for this study.

Table 3.5.2: Result of KMO test

\begin{tabular}{c|ccccccc}
\hline \multicolumn{7}{|c}{ Kaiser's Measure of Sampling Adequacy: Overall MSA $=0.91764361$} \\
\hline CHM1 & 0.92932734 & CHM11 & 0.91454427 & ENG1 & 0.91792447 & ENG11 & 0.89677713 \\
CHM2 & 0.93032458 & CHM12 & 0.91372675 & ENG2 & 0.84069785 & ENG12 & 0.8860945 \\
CHM3 & 0.93514329 & CHM13 & 0.95998643 & ENG3 & 0.85076431 & ENG13 & 0.93112615 \\
CHM4 & 0.9155534 & CHM14 & 0.934644 & ENG4 & 0.87280436 & ENG14 & 0.902861 \\
CHM5 & 0.93839069 & CHM15 & 0.94803624 & ENG5 & 0.93720945 & ENG15 & 0.90933125 \\
CH6 & 0.95212974 & CHM16 & 0.93192438 & ENG6 & 0.89789022 & ENG16 & 0.92750891 \\
CHM7 & 0.90786718 & CHM17 & 0.9365379 & ENG7 & 0.92589486 & ENG17 & 0.86636644 \\
CHM8 & 0.93850324 & CHM18 & 0.94218693 & ENG8 & 0.94317619 & ENG18 & 0.87084904 \\
CHM9 & 0.95557414 & CHM19 & 0.81345345 & ENG9 & 0.90306383 & LVL1 & 0.94562291 \\
CHM10 & 0.94125146 & CHM20 & 0.76132608 & ENG10 & 0.92587591 & & \\
\hline
\end{tabular}


Table 3.5.3: Eigenvalues table

\begin{tabular}{|c|c|c|c|c|}
\hline \multicolumn{5}{|c|}{ EIGENVALUES OF THE CORRELATION MATRIX: TOTAL } \\
\hline \multicolumn{5}{|c|}{$=39$ AVERAGE $=1$} \\
\hline & Eigenvalue & Difference & Proportion & Cumulative \\
\hline 1 & 15.31112 & 10.56166 & 0.3926 & 0.3926 \\
\hline 2 & 4.749461 & 2.698195 & 0.1218 & 0.5144 \\
\hline 3 & 2.051266 & 0.47327 & 0.0526 & 0.567 \\
\hline 4 & 1.577997 & 0.334708 & 0.0405 & 0.6074 \\
\hline 5 & 1.243289 & 0.043411 & 0.0319 & 0.6393 \\
\hline 6 & 1.199878 & 0.13317 & 0.0308 & 0.6701 \\
\hline 7 & 1.066708 & 0.168411 & 0.0274 & 0.6974 \\
\hline 8 & 0.898297 & 0.028239 & 0.023 & 0.7205 \\
\hline 9 & 0.870058 & 0.022236 & 0.0223 & 0.7428 \\
\hline 10 & 0.847822 & 0.136557 & 0.0217 & 0.7645 \\
\hline 11 & 0.711265 & 0.035219 & 0.0182 & 0.7827 \\
\hline 12 & 0.676046 & 0.072649 & 0.0173 & 0.8001 \\
\hline 13 & 0.603398 & 0.062493 & 0.0155 & 0.8156 \\
\hline 14 & 0.540905 & 0.023335 & 0.0139 & 0.8294 \\
\hline 15 & 0.51757 & 0.036924 & 0.0133 & 0.8427 \\
\hline 16 & 0.480645 & 0.023187 & 0.0123 & 0.855 \\
\hline 17 & 0.457458 & 0.018074 & 0.0117 & 0.8667 \\
\hline 18 & 0.439385 & 0.040115 & 0.0113 & 0.878 \\
\hline 19 & 0.39927 & 0.009349 & 0.0102 & 0.8883 \\
\hline 20 & 0.389921 & 0.033694 & 0.01 & 0.8983 \\
\hline 21 & 0.356227 & 0.035198 & 0.0091 & 0.9074 \\
\hline 22 & 0.321029 & 0.010243 & 0.0082 & 0.9156 \\
\hline 23 & 0.310787 & 0.021289 & 0.008 & 0.9236 \\
\hline 24 & 0.289498 & 0.0032 & 0.0074 & 0.931 \\
\hline 25 & 0.286298 & 0.01669 & 0.0073 & 0.9383 \\
\hline 26 & 0.269608 & 0.027319 & 0.0069 & 0.9453 \\
\hline 27 & 0.242289 & 0.008097 & 0.0062 & 0.9515 \\
\hline 28 & 0.234192 & 0.012124 & 0.006 & 0.9575 \\
\hline 29 & 0.222068 & 0.016026 & 0.0057 & 0.9632 \\
\hline 30 & 0.206041 & 0.012741 & 0.0053 & 0.9685 \\
\hline 31 & 0.193301 & 0.02037 & 0.005 & 0.9734 \\
\hline 32 & 0.17293 & 0.006734 & 0.0044 & 0.9778 \\
\hline 33 & 0.166196 & 0.023906 & 0.0043 & 0.9821 \\
\hline 34 & 0.14229 & 0.006659 & 0.0036 & 0.9858 \\
\hline 35 & 0.135631 & 0.006397 & 0.0035 & 0.9892 \\
\hline 36 & 0.129234 & 0.011533 & 0.0033 & 0.9925 \\
\hline 37 & 0.117701 & 0.019062 & 0.003 & 0.9956 \\
\hline 38 & 0.098639 & 0.024358 & 0.0025 & 0.9981 \\
\hline 39 & 0.074282 & & 0.0019 & 1 \\
\hline
\end{tabular}


The table 3.5.2, it shows the result of Kaiser-Meyer-Olkin (KMO) test. Kaiser-Meyer-Olkin (KMO) Test is a measure of how suited the raw data is for Factor Analysis. From the table, we can see that the overall Kaiser's measure of sampling adequacy value is 0.918 for chemistry and engagement of students. The highest value of KMO is 0.96 for the item CHM13 while the lowest value is 0.76 for item CHM20. It shows that the sample was adequate to perform the related testing.

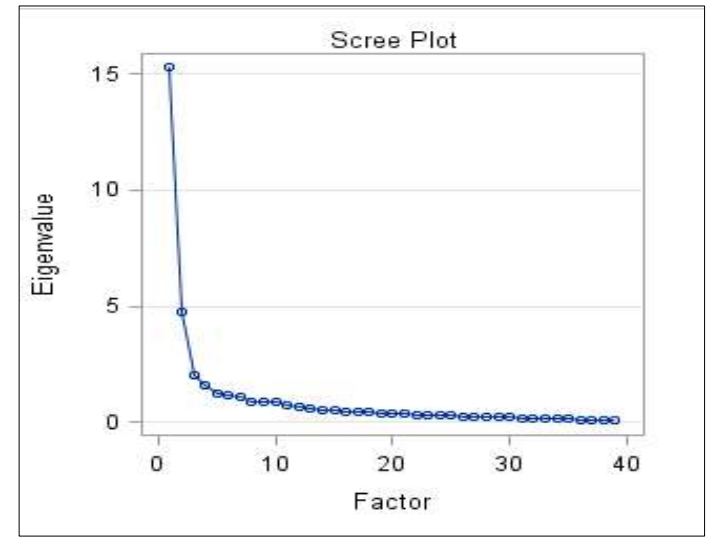

Figure 3.5.4: Scree Plot

In table 3.5.3, we can see the result using principle component analysis in correlation matrix. It shows the eigenvalue for each variable in this analysis. There are only seven variable have higher eigenvalue which is more than 1 . The first eigenvalue is 15.31112 , second 4.749461 until seven eigenvalue is 1.066708 and other is less than 1. After we get the eigenvalue, we can plot it using scree plot to more clearly in detail about what the table explain. The scree plot mainly shows the eigenvalue for each factor and from the analysis show that there is one major factor in the variables involved. In scree plot above, we use all the value from eigenvalue in the table above and then we plot it from the highest to smallest. The principal component factor analysis was done followed by rotation of varimax performed on 39 items on this study. The results of factor pattern were presented in table 3.5 .3 below that show that only 7 construct factor that determined from the analysis.

Table 3.5.5: Result of Principal Component Factor Analysis

\begin{tabular}{lrrrrrrr}
\hline & \multicolumn{7}{c}{ Factor Pattern } \\
\hline CHM17 & 0.76674 & -0.25434 & 0.07876 & 0.00564 & 0.18244 & -0.01472 & -0.07403 \\
CHM16 & 0.72705 & -0.26526 & 0.06159 & 0.03015 & 0.10362 & 0.02295 & -0.01672 \\
CHM9 & 0.72484 & -0.29027 & 0.01051 & 0.15941 & 0.04253 & -0.25449 & 0.11401 \\
CHM13 & 0.72041 & -0.10177 & 0.03132 & 0.11904 & 0.01025 & 0.01224 & 0.17573 \\
CH6 & 0.71738 & -0.3814 & 0.02137 & -0.09231 & -0.01723 & -0.0586 & -0.07978 \\
CHM7 & 0.71637 & -0.37604 & 0.04303 & 0.01481 & -0.07273 & 0.01546 & 0.0852 \\
CHM3 & 0.69982 & -0.32319 & 0.23152 & -0.24695 & -0.23369 & 0.09254 & -0.14433 \\
CHM8 & 0.69981 & -0.35875 & 0.02016 & 0.09017 & -0.05436 & -0.299 & -0.23744 \\
CHM2 & 0.69915 & -0.32788 & 0.18773 & -0.0403 & -0.23082 & 0.12968 & 0.15878 \\
CHM15 & 0.69751 & -0.36438 & 0.03804 & 0.08241 & 0.0428 & -0.17123 & -0.01794 \\
CHM10 & 0.6936 & -0.28888 & -0.1872 & 0.25589 & -0.01291 & -0.23759 & -0.07938 \\
ENG8 & 0.68684 & 0.22193 & -0.34068 & -0.07875 & -0.06573 & 0.01183 & -0.1643 \\
CHM1 & 0.68662 & -0.13414 & 0.25855 & -0.29076 & -0.17572 & 0.2221 & 0.15731 \\
CHM5 & 0.68401 & -0.36688 & 0.02491 & -0.06518 & -0.03778 & -0.0171 & -0.28833 \\
\hline
\end{tabular}




\begin{tabular}{lrrrrrrr}
\hline ENG17 & 0.68066 & 0.08653 & -0.31977 & -0.29621 & 0.3593 & 0.07606 & 0.1636 \\
ENG18 & 0.67271 & 0.07364 & -0.32979 & -0.29252 & 0.35293 & 0.12927 & 0.07579 \\
ENG7 & 0.66748 & 0.45223 & -0.13775 & 0.08468 & -0.18305 & 0.06931 & -0.22328 \\
ENG1 & 0.66696 & 0.11574 & 0.00915 & -0.31664 & -0.22869 & 0.20034 & 0.07608 \\
CHM12 & 0.65333 & -0.26728 & -0.17276 & 0.29013 & 0.09761 & -0.00232 & 0.37163 \\
CHM11 & 0.64874 & -0.37793 & -0.1727 & 0.33939 & 0.152 & -0.03985 & 0.20825 \\
CHM4 & 0.63633 & -0.2973 & 0.23181 & -0.17443 & -0.15139 & 0.05619 & -0.02741 \\
CHM14 & 0.63524 & -0.38795 & 0.06389 & -0.12156 & 0.0006 & -0.04317 & 0.00487 \\
CHM18 & 0.63387 & -0.162 & 0.1934 & 0.25446 & 0.137 & 0.08087 & -0.32743 \\
ENG11 & 0.63221 & 0.53426 & 0.10356 & 0.03153 & -0.12257 & -0.29512 & 0.13928 \\
ENG16 & 0.61066 & 0.2909 & -0.18044 & -0.32667 & 0.37895 & -0.01032 & -0.09645 \\
ENG12 & 0.60878 & 0.47149 & 0.12771 & -0.1745 & -0.23733 & -0.14918 & 0.10104 \\
ENG10 & 0.60616 & 0.53309 & 0.02591 & 0.00073 & -0.03006 & -0.16843 & 0.18647 \\
ENG6 & 0.57284 & 0.48327 & -0.17769 & 0.04606 & -0.22802 & 0.13837 & -0.16414 \\
ENG4 & 0.56474 & 0.0805 & -0.39443 & 0.26363 & -0.0726 & 0.28516 & -0.32791 \\
ENG14 & 0.562 & 0.45839 & 0.2025 & -0.09575 & 0.30013 & -0.25052 & -0.1152 \\
ENG5 & 0.54735 & 0.37028 & -0.19491 & 0.12531 & -0.26069 & -0.11915 & -0.02981 \\
LVL1 & 0.50878 & -0.15177 & 0.03688 & -0.12172 & -0.11398 & 0.17601 & 0.31622 \\
ENG15 & 0.50629 & 0.34476 & 0.22913 & -0.31954 & 0.21184 & -0.06844 & -0.13738 \\
ENG9 & 0.49094 & 0.63293 & -0.15955 & 0.20825 & -0.20509 & -0.16371 & 0.15841 \\
ENG13 & 0.55359 & 0.59285 & -0.09272 & 0.02884 & 0.018 & -0.04707 & 0.03681 \\
CHM19 & 0.44453 & 0.27681 & 0.53832 & 0.35753 & 0.11788 & 0.17797 & -0.04574 \\
ENG2 & 0.22731 & 0.39741 & 0.50283 & 0.07289 & 0.05563 & 0.25696 & -0.03585 \\
CHM20 & 0.34449 & 0.40516 & 0.49957 & 0.34079 & 0.28011 & 0.16896 & 0.08393 \\
ENG3 & 0.45561 & 0.08656 & -0.37029 & 0.23586 & 0.04065 & 0.54173 & 0.06208 \\
\hline & & & & & & & \\
& & & & & &
\end{tabular}

Table 3.5.6: Final Communality Estimate table

\begin{tabular}{cccccccc}
\hline \multicolumn{7}{c}{ Final Communality Estimates: Total = 27.199720 } \\
\hline CHM1 & 0.745779 & CHM11 & 0.77677 & ENG1 & 0.656797 & ENG11 & 0.818367 \\
CHM2 & 0.72849 & CHM12 & 0.759942 & ENG2 & 0.538159 & ENG12 & 0.728468 \\
CHM3 & 0.792799 & CHM13 & 0.575632 & ENG3 & 0.706792 & ENG13 & 0.671258 \\
CHM4 & 0.604289 & CHM14 & 0.574781 & ENG4 & 0.744593 & ENG14 & 0.742259 \\
CHM5 & 0.69219 & CHM15 & 0.659003 & ENG5 & 0.573436 & ENG15 & 0.598231 \\
CH6 & 0.679167 & CHM16 & 0.615213 & ENG6 & 0.693465 & ENG16 & 0.749811 \\
CHM7 & 0.669443 & CHM17 & 0.697798 & ENG7 & 0.764355 & ENG17 & 0.822421 \\
CHM8 & 0.775703 & CHM18 & 0.662706 & ENG8 & 0.674716 & ENG18 & 0.7993 \\
CHM9 & 0.714744 & CHM19 & 0.739513 & ENG9 & 0.8044 & LVL1 & 0.442034 \\
CHM10 & 0.727974 & CHM20 & 0.762587 & ENG10 & 0.716336 & & \\
\hline
\end{tabular}

In the table above, we can see these communalities show the uniqueness of each original variable and we can see at the table above that CHM1, CHM2, CHM3, CHM5, CH6, CHM7, CHM8, CHM9, CHM10, CHM11, CHM12, CHM15, CHM17, CHM18, CHM19, CHM20, ENG1, ENG3, ENG4, ENG6, ENG7, ENG8, ENG9, ENG10, ENG11, ENG12, ENG13, ENG14, ENG16, ENG17 and ENG18 have more than 0.7 which means that has higher community and this variable has a low uniqueness factor. Then, the factor analysis with varimax rotation was performed. The rotation can 
help in improved the data interpretation and reduce skewness in the distribution. The result of rotated factor pattern was shown in table below.

Table 3.5.7: Result from rotated factor pattern

\begin{tabular}{|c|c|c|c|c|c|c|c|}
\hline \multicolumn{8}{|c|}{ Rotated Factor Pattern } \\
\hline & Factor1 & Factor2 & Factor3 & Factor4 & Factor5 & Factor6 & Factor7 \\
\hline CHM8 & 0.84728 & 0.1968 & 0.04642 & -0.0295 & -0.0103 & 0.01643 & -0.1252 \\
\hline CHM15 & 0.78277 & 0.12117 & 0.11835 & 0.03864 & 0.09259 & 0.01839 & 0.08472 \\
\hline CHM10 & 0.7738 & 0.25833 & 0.04626 & -0.0792 & -0.0939 & 0.17115 & 0.12627 \\
\hline СНM9 & 0.77083 & 0.23216 & 0.0988 & 0.04231 & 0.05096 & -0.0308 & 0.22708 \\
\hline CH6 & 0.75395 & 0.08783 & 0.18457 & -0.0185 & 0.24903 & 0.07272 & -0.036 \\
\hline CHM5 & 0.74754 & 0.06475 & 0.15079 & 0.00739 & 0.1803 & 0.16838 & -0.2134 \\
\hline СНM17 & 0.72596 & 0.11205 & 0.30086 & 0.1851 & 0.14386 & 0.10836 & 0.03181 \\
\hline СНM7 & 0.72414 & 0.09826 & 0.08371 & 0.03298 & 0.31476 & 0.10197 & 0.13354 \\
\hline CHM11 & 0.71656 & 0.06585 & 0.0918 & 0.02368 & -0.0174 & 0.21543 & 0.45086 \\
\hline СНM16 & 0.68674 & 0.10793 & 0.22206 & 0.15312 & 0.19031 & 0.13032 & 0.07742 \\
\hline СНM14 & 0.68041 & 0.02841 & 0.1765 & -0.0087 & 0.28192 & 0.00723 & 0.01596 \\
\hline СНM3 & 0.66195 & 0.09841 & 0.07858 & 0.07622 & 0.5214 & 0.05231 & -0.2416 \\
\hline СНM18 & 0.64155 & 0.08191 & 0.08809 & 0.38605 & -0.0309 & 0.25826 & -0.1413 \\
\hline CHM2 & 0.64006 & 0.11851 & -0.0248 & 0.1123 & 0.5229 & 0.07577 & 0.11125 \\
\hline СНM12 & 0.60866 & 0.15749 & 0.10167 & 0.02833 & 0.09879 & 0.18478 & 0.55645 \\
\hline CHM4 & 0.60672 & 0.08096 & 0.07951 & 0.10783 & 0.44827 & -0.0022 & -0.1035 \\
\hline СНM13 & 0.5686 & 0.27782 & 0.1388 & 0.16955 & 0.22092 & 0.12201 & 0.25187 \\
\hline ENG9 & 0.01137 & 0.8559 & 0.03466 & 0.12532 & -0.0091 & 0.13663 & 0.18988 \\
\hline ENG11 & 0.2002 & 0.81722 & 0.1481 & 0.24158 & 0.09458 & -0.1234 & 0.07727 \\
\hline ENG10 & 0.13159 & 0.7389 & 0.24704 & 0.23431 & 0.11978 & -0.0325 & 0.14733 \\
\hline ENG12 & 0.15199 & 0.73197 & 0.16236 & 0.17213 & 0.31968 & -0.0922 & -0.0538 \\
\hline ENG13 & 0.04598 & 0.70786 & 0.29624 & 0.22469 & 0.03764 & 0.15674 & 0.06205 \\
\hline ENG5 & 0.20799 & 0.69237 & 0.02261 & 0.00268 & 0.05041 & 0.21789 & 0.01648 \\
\hline ENG7 & 0.22376 & 0.69128 & 0.15089 & 0.17081 & 0.09884 & 0.38949 & -0.1517 \\
\hline ENG6 & 0.09935 & 0.66645 & 0.12841 & 0.1231 & 0.15389 & 0.41151 & -0.1216 \\
\hline ENG8 & 0.33909 & 0.54021 & 0.33263 & -0.0869 & 0.10541 & 0.36434 & -0.0766 \\
\hline ENG14 & 0.21628 & 0.5259 & 0.46627 & 0.39506 & -0.0841 & -0.154 & -0.121 \\
\hline ENG16 & 0.21584 & 0.36306 & 0.73593 & 0.0861 & 0.06127 & 0.12085 & -0.0636 \\
\hline ENG17 & 0.31884 & 0.26781 & 0.72406 & -0.0494 & 0.193 & 0.1873 & 0.22363 \\
\hline ENG18 & 0.32019 & 0.2356 & 0.71866 & -0.043 & 0.18514 & 0.2558 & 0.15248 \\
\hline ENG15 & 0.16092 & 0.36678 & 0.49097 & 0.31776 & 0.15829 & -0.1209 & -0.2369 \\
\hline СНM20 & 0.04969 & 0.24113 & 0.08458 & 0.81887 & -0.02 & 0.02457 & 0.15257 \\
\hline CHM19 & 0.21875 & 0.24191 & -0.0402 & 0.7883 & 0.05477 & 0.08186 & 0.02019 \\
\hline ENG2 & -0.0848 & 0.20357 & 0.03804 & 0.66255 & 0.19426 & 0.02128 & -0.1044 \\
\hline CHM1 & 0.45363 & 0.16802 & 0.1714 & 0.18179 & 0.66991 & 0.02364 & 0.00095 \\
\hline ENG1 & 0.28364 & 0.39203 & 0.2456 & 0.04395 & 0.57478 & 0.16419 & -0.0555 \\
\hline LVL1 & 0.33801 & 0.11911 & 0.11253 & 0.03614 & 0.48123 & 0.07046 & 0.25116 \\
\hline ENG3 & 0.13383 & 0.15044 & 0.17115 & 0.09813 & 0.16326 & 0.72114 & 0.28396 \\
\hline ENG4 & 0.34509 & 0.31261 & 0.10457 & 0.01299 & -0.0349 & 0.71496 & -0.0655 \\
\hline
\end{tabular}

The result from factor rotation indicates 7 factors and has been organized from highest factor loading to lowest factor loading. For this analysis, the significant loading cut-off above 0.40 to make interpretation easier for all 7 factor items for varimax rotation. Factor 1 comprises 18 items with the 
factor loading ranging from 0.45 to 0.85 . In factor 2 comprises 10 items with the factor loading ranging from 0.52 to 0.85 . For factor 3 comprises 5 items with the factor loading ranging from 0.47 to 0.73 . Factor 4 comprises 3 items with the factor loading ranging from 0.66 to 0.79 . In addition, factor 5 comprises 6 items with the factor loading ranging from 0.45 to 0.67 . In factor 6 comprises 3 items with the factor loading ranging from 0.41 to 0.72 . For the remaining factor 7 comprises 2 items with the factor loading ranging 0.45 and 0.56 .

But the items that comprises in factor 7 same with the factor 1 , so the highest loading factor will be chosen. The items that have in factor 1 and factor 7 was CHM11 and CHM12. The loading factor of CHM1 1 were 0.72 in factor 1 and 0.45 in factor 7 , the highest loading factor of CHM1 1 item is 0.72 and shows that CHM11 being with factor 1 . For second item that same in factor 1 and factor 7 was CHM12, the loading factor of CHM12 in factor 1 were 0.61 and 0.56 in factor 7 and the loading factor of CHM12 high in factor 1 than the factor 7. Besides that, the factor 5 comprises 4 same items as factor 1. From all the 4 same items, the loading factor in 3 items were high in factor 1 while the other 1 item which is CHM1, the loading factor was high in factor 5 than factor 1 . It shows that CHM1 item belong to the factor 5 .

Table 3.5.8: Result of remain factors

\begin{tabular}{|c|c|c|c|c|c|c|}
\hline & $\begin{array}{l}\text { Factor1 } \\
\text { (Chemistry } \\
\text { with } \\
\text { friends) }\end{array}$ & $\begin{array}{l}\text { Factor2 } \\
\text { (Students' } \\
\text { Engagemen } \\
\text { t) }\end{array}$ & $\begin{array}{l}\text { Factor3 } \\
\text { (Students' } \\
\text { Involveme } \\
\text { nt) }\end{array}$ & $\begin{array}{l}\text { Factor4 } \\
\text { (Similarity } \\
\text { with } \\
\text { friends) }\end{array}$ & $\begin{array}{l}\text { Factor5 } \\
\text { (Students' } \\
\text { contribution } \\
\text { ) }\end{array}$ & $\begin{array}{l}\text { Factor6 } \\
\text { (Cooperate } \\
\text { with } \\
\text { friends) }\end{array}$ \\
\hline $\begin{array}{l}\text { My friend finds me funny and } \\
\text { interesting }\end{array}$ & 0.84728 & & & & & \\
\hline $\begin{array}{l}\text { I get excited to talk to or see my } \\
\text { friend }\end{array}$ & 0.78277 & & & & & \\
\hline $\begin{array}{l}\text { My friend and I find the same } \\
\text { things funny }\end{array}$ & 0.7738 & & & & & \\
\hline $\begin{array}{l}\text { I find my friend funny and } \\
\text { interesting }\end{array}$ & 0.77083 & & & & & \\
\hline $\begin{array}{l}\text { My friend feels that he/she can } \\
\text { trust me }\end{array}$ & 0.75395 & & & & & \\
\hline $\begin{array}{l}\text { The communication between } \\
\text { my friend and } I \text { is easy and } \\
\text { effortless }\end{array}$ & 0.74754 & & & & & \\
\hline $\begin{array}{l}\text { I like my friend because he/she } \\
\text { likes me }\end{array}$ & 0.72596 & & & & & \\
\hline I feel like I can trust my friend & 0.72414 & & & & & \\
\hline $\begin{array}{l}\text { I feel good when I am around } \\
\text { my friend }\end{array}$ & 0.71656 & & & & & \\
\hline $\begin{array}{l}\text { My friend cares about the } \\
\text { general well-being of other } \\
\text { people }\end{array}$ & 0.68674 & & & & & \\
\hline $\begin{array}{l}\text { I care about the general well- } \\
\text { being of other people }\end{array}$ & 0.68041 & & & & & \\
\hline $\begin{array}{l}\text { I feel like I really understand } \\
\text { my friend }\end{array}$ & 0.66195 & & & & & \\
\hline
\end{tabular}




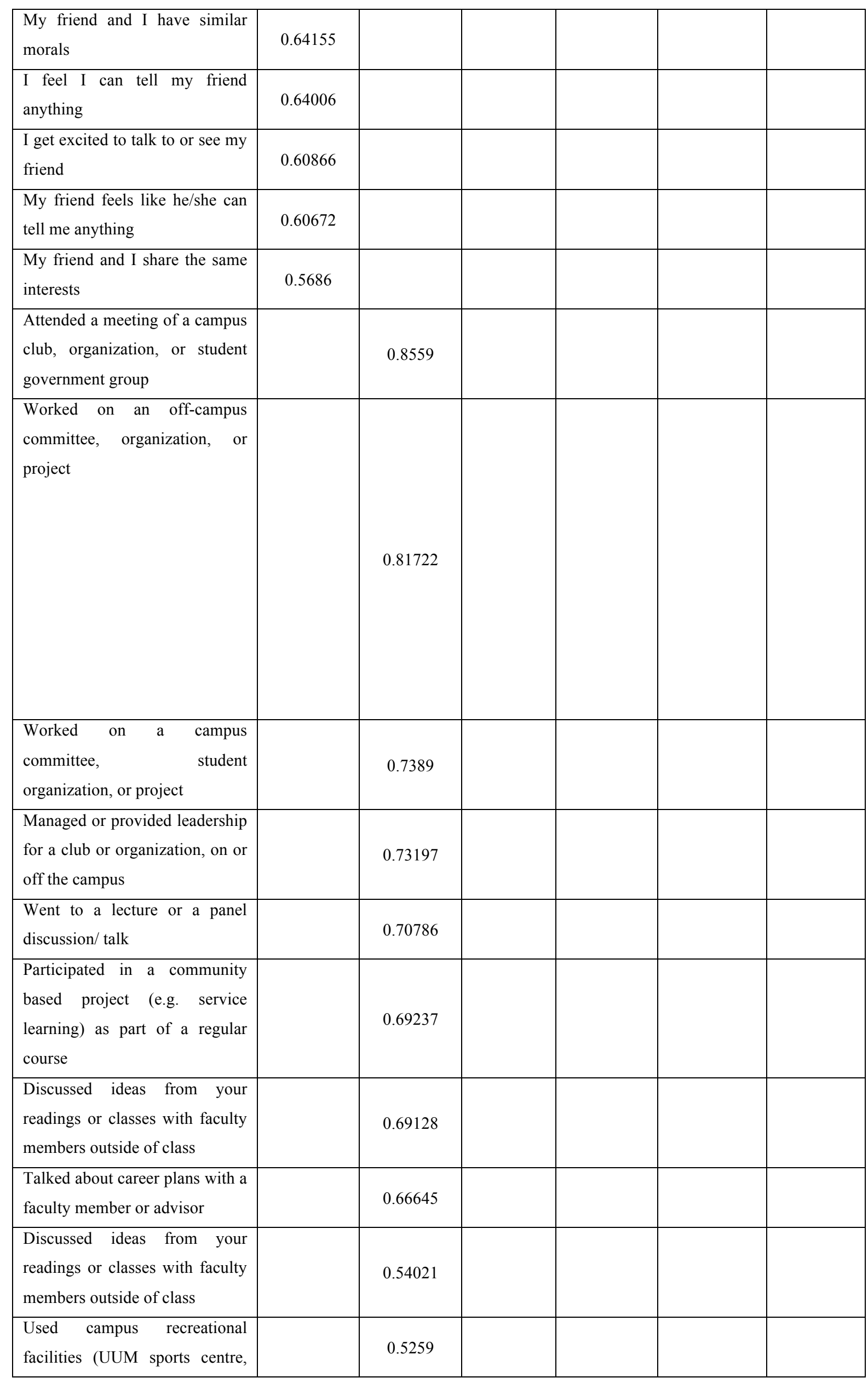




\begin{tabular}{|c|c|c|c|}
\hline $\begin{array}{l}\text { pool, fitness equipment, courts, } \\
\text { etc.) }\end{array}$ & & & \\
\hline $\begin{array}{l}\text { Participated in activities to } \\
\text { enhance your spiritually } \\
\text { (worship, meditation, prayer, } \\
\text { etc.) }\end{array}$ & 0.73593 & & \\
\hline $\begin{array}{l}\text { Tried to better } \text { understand } \\
\text { someone else's views by } \\
\text { imaging how an issue looks } \\
\text { from his or her perspective }\end{array}$ & 0.72406 & & \\
\hline $\begin{array}{l}\text { Learned something that changed } \\
\text { the way you understand an issue } \\
\text { or concept }\end{array}$ & 0.71866 & & \\
\hline Played a team sport & 0.49097 & & \\
\hline $\begin{array}{l}\text { My friend and I have a similar } \\
\text { level of education }\end{array}$ & & 0.81887 & \\
\hline $\begin{array}{l}\text { My friend and I have the same } \\
\text { life goals }\end{array}$ & & 0.7883 & \\
\hline \begin{tabular}{llr|} 
Come to & class & without \\
completing & readings & or \\
assignments & & \\
\end{tabular} & & 0.66255 & \\
\hline $\begin{array}{l}\text { I feel like my friend really } \\
\text { understands me }\end{array}$ & & & 0.66991 \\
\hline
\end{tabular}




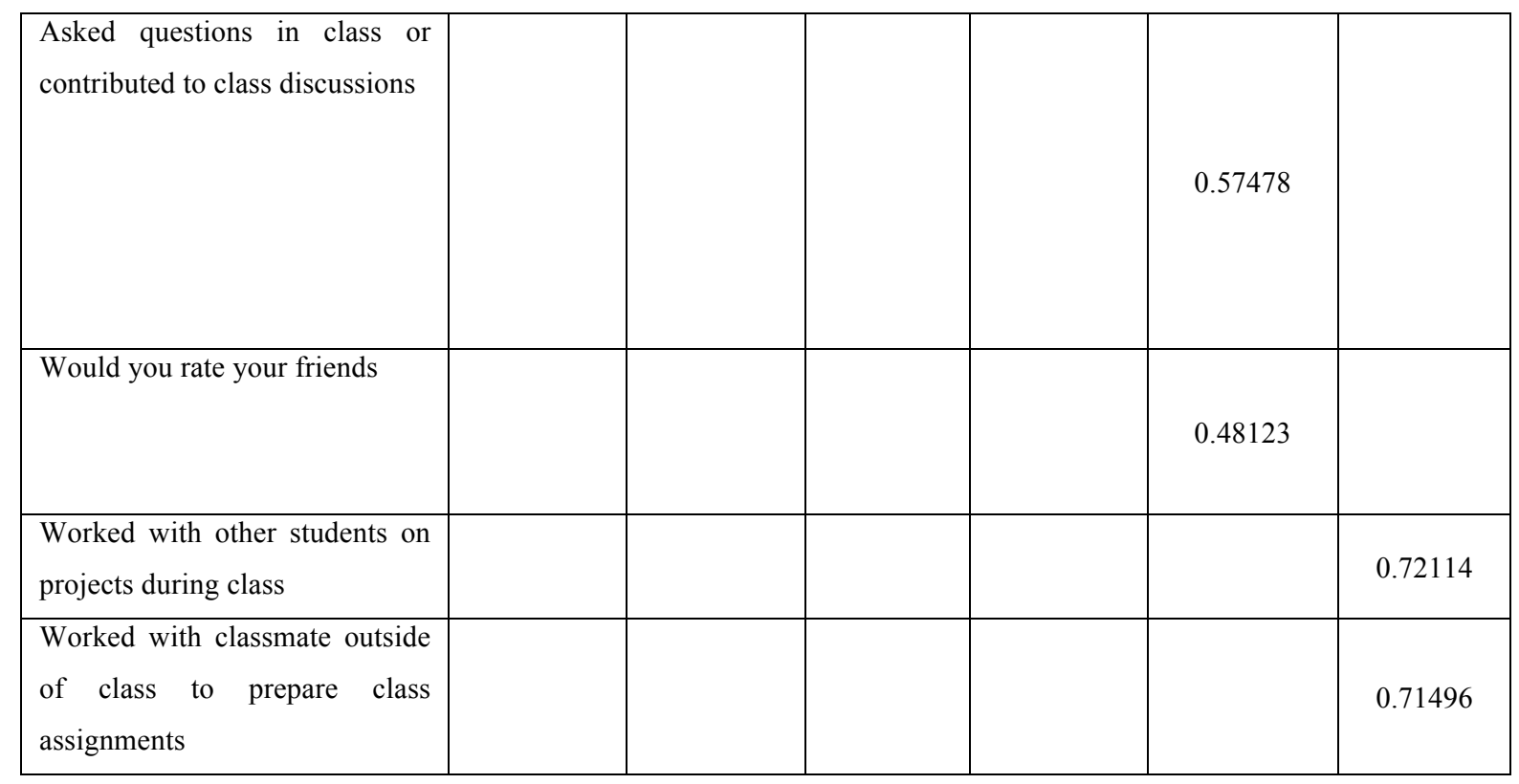

Table above shows the result of remain factors. We can see each factor was naming with suitable name that fixed with the items that chosen in each factor. The factor 1 was name as chemistry with their friends as the all items was about the chemistry of their friendship. Name the factor 2 as the students' engagements in the university. For factor 3, the items were about the participation or involvement of students so we name the factor 3 as students' involvement. The factor 4 names as the similarity with their friends as the items in factor 4 were about the similarity between their friends. Lastly, the factor 6 was about the cooperation with their friends in university.

\section{Normality test}

Before deciding which test to use, first the researcher test normality (refer to APPENDIX 1) to know whether the data is normal or non-normal. From this analysis, the normality test is non-normal. Therefore, researcher decide to use Chi Square Test and Spearman Rho Test. Appendix 1 will show result that was test for each factor in this study. Mean for each factor will be used when to see the normality test, this is because it easy to test the mean of all the variables for each factor.

\section{Spearman Rho Test (Spearman Correlation}

Spearman Rho Test used in order to see the relationship between all factors test in previous section and level of friendship. Mean for each factor will be used to run the Spearman Correlation and Chi-Square. For Chi-square, the analysis was to see the relationship between gender and chemistry, engagement.

Table 3.7.1: Simple Statistic table for all factors

\begin{tabular}{lcrrrrr}
\hline \multicolumn{7}{c}{ Simple Statistics } \\
\hline Variable & N & Mean & Std Dev & Median & Minimum & Maximum \\
\hline LVL1 & 241 & 4.51 & 0.7195 & 5 & 1 & 5 \\
MEAN F1 & 241 & 4.31 & 0.5459 & 4.35 & 2.59 & 5 \\
MEAN F2 & 241 & 3.89 & 0.7602 & 4 & 1.7 & 5 \\
MEAN F3 & 241 & 3.98 & 0.7417 & 4 & 1 & 5 \\
MEAN F4 & 241 & 3.76 & 0.8797 & 4 & 1.67 & 5 \\
MEAN F5 & 241 & 4.29 & 0.6901 & 4.33 & 2.33 & 5 \\
MEAN F6 & 241 & 4.30 & 0.6236 & 4.5 & 2.5 & 5 \\
\hline
\end{tabular}


Table 3.7.2: Spearman Correlation for Mean of all factor 1 until factor 6

\begin{tabular}{|c|c|c|c|c|c|c|c|}
\hline \multicolumn{8}{|c|}{ Spearman Correlation Coefficients, $N=241$} \\
\hline \multicolumn{8}{|c|}{ Prob $>|\mathbf{r}|$ under H0: Rho $=0$} \\
\hline & LVL1 & $\begin{array}{l}\text { MEAN } \\
\text { F1 }\end{array}$ & $\begin{array}{l}\text { MEAN } \\
\text { F2 }\end{array}$ & $\begin{array}{c}\text { MEAN } \\
\text { F3 }\end{array}$ & $\begin{array}{c}\text { MEAN } \\
\text { F4 }\end{array}$ & $\begin{array}{c}\text { MEAN } \\
\text { F5 }\end{array}$ & $\begin{array}{l}\text { MEAN } \\
\text { F6 }\end{array}$ \\
\hline \multirow[t]{2}{*}{ LVL1 } & 1 & 0.51714 & 0.32481 & 0.3910 & 0.2160 & 0.7325 & 0.2965 \\
\hline & & $<.0001$ & $<.0001$ & $<.0001$ & 0.0007 & $<.0001$ & $<.0001$ \\
\hline \multirow[t]{2}{*}{ MEAN F1 } & 0.5171 & 1 & 0.4504 & 0.5922 & 0.2511 & 0.67469 & 0.4484 \\
\hline & $<.0001$ & & $<.0001$ & $<.0001$ & $<.0001$ & $<.0001$ & $<.0001$ \\
\hline \multirow[t]{2}{*}{ MEAN F2 } & 0.3248 & 0.4504 & 1 & 0.6760 & 0.5416 & 0.5124 & 0.4505 \\
\hline & $<.0001$ & $<.0001$ & & $<.0001$ & $<.0001$ & $<.0001$ & $<.0001$ \\
\hline \multirow[t]{2}{*}{ MEAN F3 } & 0.3910 & 0.5922 & 0.6760 & 1 & 0.3265 & 0.6075 & 0.3892 \\
\hline & $<.0001$ & $<.0001$ & $<.0001$ & & $<.0001$ & $<.0001$ & $<.0001$ \\
\hline \multirow[t]{2}{*}{ MEAN F4 } & 0.2156 & 0.2511 & 0.5416 & 0.3265 & 1 & 0.3541 & 0.201 \\
\hline & 0.0007 & $<.0001$ & $<.0001$ & $<.0001$ & & $<.0001$ & 0.0017 \\
\hline \multirow[t]{2}{*}{ MEAN F5 } & 0.7325 & 0.6746 & 0.5124 & 0.6075 & 0.3541 & 1 & 0.4001 \\
\hline & $<.0001$ & $<.0001$ & $<.0001$ & $<.0001$ & $<.0001$ & & $<.0001$ \\
\hline \multirow[t]{2}{*}{ MEAN F6 } & 0.2967 & 0.4484 & 0.4505 & 0.3892 & 0.201 & 0.4001 & 1 \\
\hline & $<.0001$ & $<.0001$ & $<.0001$ & $<.0001$ & 0.0017 & $<.0001$ & \\
\hline
\end{tabular}

Spearman's correlation determines the direction and strength of the monotonic relationship between two variables rather than the strength and direction of the linear relationship. In Table 3.6.1, shows the result of correlation between the entire factor. So, these are all the inter correlation we have here and when we look at this off diagonal where these one here are the diagonal and they are just having the value of 1 because the variable is correlated with itself which is Level of friendship (LVL) correlated with LVL, Chemistry (Mean Factor 1) correlated with Chemistry (Mean Factor 1) and so on. In addition, all of the other off diagonal in Table 3.6.2 represents the correlation of the factor with one another. So, for example the correlation Level of friendship (LVL) and Chemistry (Mean F1) was 0.5171, LVL and Engagement (Mean F2) was 0.3248, Level of friendship (LVL) with Involvement (Mean F3) was 0.3910, Level of friendship (LVL) and Similarity (Mean F4) was 0.2156, Level of friendship (LVL) and Contribution (Mean F5) was 0.7325 and Level of friendship (LVL) with Cooperation (Mean F6) was 0.2967. As we can see Table 3.6.2 above, the strong relationship between levels of friendship was from combination of Level of friendship (LVL) and Chemistry (Mean F1). It shows 0.7325 among these two variables. When the Chemistry (Mean F1) correlated with Engagement (Mean F2), and Involvement (Mean F3), it also shows the higher value among them which more than 0.5. Mostly factor in the Table 3.6.2 show the moderate correlation between each factor but only certain factor has strong correlation. Figure 3.6.1 shows the relationship has among LVL and all factor in graphical Scatter plot. 


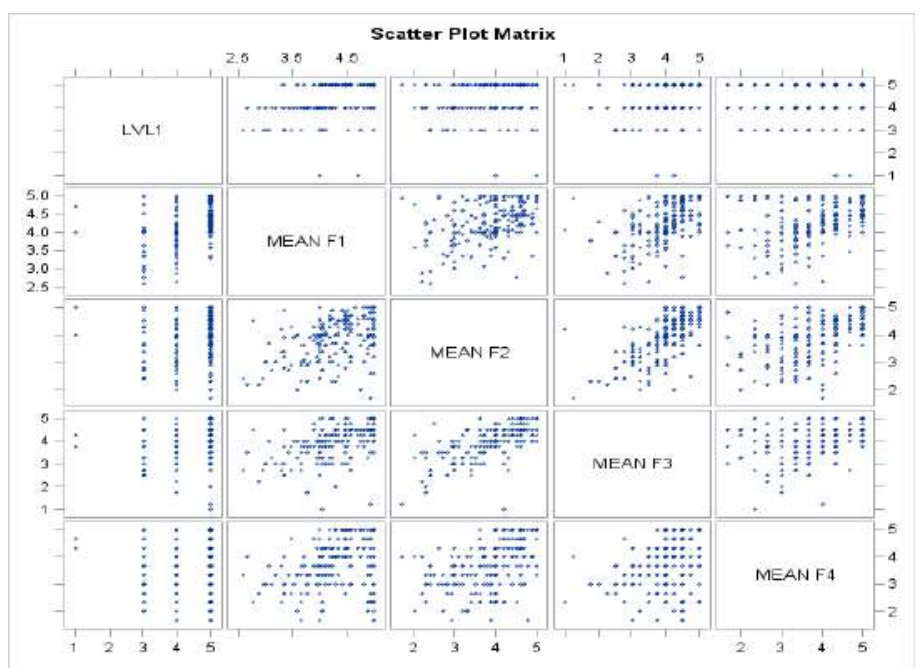

Figure 3.7.1: Scatter Plot for all factor used with Level of friendship

\section{Chi Square Test (Relationship in gender with Chemistry and Engagement)}

To determine whether the Gender which is the Female and Male was a factor in whether the chemistry affect their friendships. The records of 241 come from SQS student where we combine both gender with Chemistry among their friendship in UUM.

Table 3.8.1 Chi Square test between Gender (Female/Male) and Chemistry

\begin{tabular}{|c|c|c|c|c|c|}
\hline \multicolumn{6}{|c|}{$\begin{array}{c}\text { CHI SQUARE TEST GENDER AND CHEMISTRY } \\
\text { The FREQ Procedure }\end{array}$} \\
\hline \multirow[t]{6}{*}{ Frequency } & \multicolumn{5}{|c|}{ Table of GENDER by MEANSCORECHEMISTRY } \\
\hline & \multirow[b]{2}{*}{ GENDER } & \multicolumn{4}{|c|}{ MEANSCORECHEMISTRY } \\
\hline & & $2.60-3.3$ & $3.40-4.1$ & $4.20-5.0$ & Total \\
\hline & Female & 13 & 65 & 99 & 177 \\
\hline & Male & 5 & 19 & 40 & 64 \\
\hline & Total & 18 & 84 & 139 & 241 \\
\hline
\end{tabular}

Statistics for Table of GENDER by MEANSCORECHEMISTRY

\begin{tabular}{|l|r|r|r|}
\hline Statistic & DF & Value & Prob \\
\hline Chi-Square & 2 & 1.0329 & 0.5966 \\
\hline Likelihood Ratio Chi-Square & 2 & 1.0499 & 0.5916 \\
\hline Mantel-Haenszel Chi-Square & 1 & 0.4361 & 0.5090 \\
\hline Phi Coefficient & & 0.0655 & \\
\hline Contingency Coefficient & 0.0653 & \\
\hline Cramer's V & 0.0655 & \\
\hline
\end{tabular}


Hypothesis Statement:

$\mathrm{H}_{0}=$ There is no relationship between difference Gender in their Chemistry in Friendship.

$\mathrm{H}_{1}=$ There is relationship between difference Gender in their Chemistry in Friendship.

$$
\begin{gathered}
d f=(r-1)(c-1) \\
d f=(2-1)(3-1)=2
\end{gathered}
$$

From the formulae above, we can find the degree of freedom. This Degree of freedom we will use to find the value of Chi-Square using the table distribution. The value of degree of freedom is 2 . In this study we use $\alpha=0.05$. The chi-square value shown at figure above is 1.0329 . Then, we look at Chi Square table distribution in Appendix 2, we will get $\boldsymbol{X}_{\text {Table }}^{2}=\mathbf{5 . 9 9}$. The result will be compare in order to know the relationship whether we reject $H_{o}$ or we do not reject $H_{o}$.

$$
\begin{gathered}
X_{S T A T}^{2}>X_{\text {Table }}^{2} \\
1.0329<5.99
\end{gathered}
$$

When the $X_{S T A T}^{2}<X_{\text {Table }}^{2}$, we do not reject $H_{o}$. When we look at the P-Value, it shown that the value is 0.5956 . This P-value is less than $\alpha$ which is 0.05 . So, that means we cannot reject $H_{o}$.

$$
0.5956>0.05 \text { Do Not Reject } H_{o}
$$

There is sufficient evidence to do not reject the claim $\left(H_{o}\right)$. That means there is no relationship among difference Gender and Chemistry in their friendship. In friendship, it not necessarily involves the difference gender; chemistry in the friendship can be created if it is from the same gender. Among the reasons for the divergence in friendship patterns is how women and men make friends. According to article from Schmeiser (2017), she found that a man needed friends to do joint activities such as involvement in military activities, curriculum activities and to sit down and talk about their difficult situation. They need to have chemistry in doing those activities because they can join their friend madness. While for women, they need chemistry in their friendship because of the shared circumstances, in which they can relate to all the sadness and frustration that can give them spirit to face that challenge. In addition, they put their trust in themselves and their friends. The most common finding is that men's friendships tend to be more "instrumental" and less emotional, while women are much more likely than men to share emotions and feelings. So, it shows that difference gender show difference pattern in their friendship.

Table 3.8.1 Chi Square test between Gender (Female/Male) and Engagement

\section{CHI SQUARE TEST GENDER AND ENGAGEMENT STUDENT}

The FREQ Procedure

\begin{tabular}{|l|l|r|r|r|r|r|r|}
\hline Frequency & \multicolumn{6}{|c|}{ Table of GENDER by MEANSCOREENGAGEMENT } \\
\hline & & \multicolumn{5}{|c|}{ MEANSCOREENGAGEMENT } \\
\cline { 2 - 9 } & GENDER & $\mathbf{1 . 0 0 - 1 . 7}$ & $\mathbf{1 . 8 0 - 2 . 5}$ & $\mathbf{2 . 6 0 - 3 . 3}$ & $\mathbf{3 . 4 0 - 4 . 1}$ & $\mathbf{4 . 2 0 - 5 . 0}$ & Total \\
\hline Female & 1 & 9 & 29 & 63 & 75 & 177 \\
\hline Male & 0 & 6 & 13 & 21 & 24 & 64 \\
\hline Total & 1 & 15 & 42 & 84 & 99 & 241 \\
\hline
\end{tabular}




\section{Statistics for Table of GENDER by MEANSCOREENGAGEMENT}

\begin{tabular}{|l|r|r|r|}
\hline Statistic & DF & Value & Prob \\
\hline Chi-Square & 4 & 2.5438 & 0.6368 \\
\hline Likelihood Ratio Chi-Square & 4 & 2.6791 & 0.6129 \\
\hline Mantel-Haenszel Chi-Square & 1 & 1.3371 & 0.2475 \\
\hline Phi Coefficient & & 0.1027 & \\
\hline Contingency Coefficient & & 0.1022 & \\
\hline Cramer's V & & 0.1027 & \\
\hline
\end{tabular}

Hypothesis Statement:

$\mathrm{H}_{0}=$ There is no relationship between different gender in their engagement in study

$\mathrm{H}_{1}=$ There is relationship between different gender in their engagement in study

$$
\begin{gathered}
d f=(r-1)(c-1) \\
d f=(2-1)(5-1)=4
\end{gathered}
$$

Degree of freedom about the combination between difference gender and their engagement was 4 which is we use the formulae above to get the answer. We use $\alpha=0.05$ to know the relationship between this variable. At the table above, we get the value of Chi-Square Statistic which is 2.5438. To test the relationships, we need to look at Chi Square table distribution. In Chi-Square table distribution, we will get $\boldsymbol{X}_{\text {Table }}^{2}=\mathbf{9 . 4 9}$. So, the result will be like below:

$$
\begin{aligned}
& \mathrm{X}_{\text {STAT }}^{2}>\mathrm{X}_{\text {Table }}^{2} \\
& 2.5438>9.49
\end{aligned}
$$

When the $X_{S T A T}^{2}<X_{\text {Table }}^{2}$, we do not reject $H_{o}$. When we look at the P-Value, it shown that the value is 0.6368 . This P-value is less than $\alpha$ which is 0.05 . So that mean we can reject $H_{o}$.

$$
0.6368>0.05 \text { do not reject } H_{o}
$$

There is sufficient evidence to do not reject the claim $\left(H_{o}\right)$. That means there is no relationship between difference gender in their engagement while study. As we know, the pattern of their interest between difference genders was difference also. Most Male prefers rugged activities such as football, futsal and many other things and while Female, and they prefer activities such as hiking, storytelling and activities with their friends. According to article Ronald (2014), he said that most women share their feelings among their friends, while men share activities together such as sport activities. In his previous study, Ronald found that men were more likely to engage in activities involving cars, activities such as traveling or doing sports activities together. Meanwhile, for women Ronald found that these women called their friends more often, met and talked more often. It shows it no relationship between difference genders in their engagement. That mean, women and men have their own pattern in friendship. 


\section{Discussion}

The main purpose of this study was to develop an instrument to measure the friendship instrument for chemistry, engagement and achievement of the SQS students in UUM. The 3 aspects of the Friendship Instrument consist of the level of friendship, chemistry with friends and the engagement of the students. In this study, the validity of this study was determined by the content validity with the expertise then proceeds with the pilot study. Then, the Cronbach's alpha has been used to measures reliability or internal consistency of the variables collected for each variable contained in the friendship study instrument based on chemistry and engagement. George and Mallery (2003) provide the following rules of thumb: “> $>.9$ - Excellent, _>.8 - Good, >.7 - Acceptable,_>.6-Questionable, $>.5$ - Poor, and _<.5 - Unacceptable". The result Cronbach's Coefficient Alpha show for overall items was 0.9553 which is it indicate excellent internal consistency of items. This will be express that the Friendship Instrument be considered reliable.

The final step of the analysis was conducted using the factor analysis to determine the correlation between construct items. Factor analysis operates on the notion that measurable and observable variables can be reduced to fewer latent variables that share a common variance and are unobservable, which is known as reducing dimensionality (Bartholomew, Knott, \& Moustaki, 2011). From the factor rotation indicates 7 factors develop from the analysis. The loading factor of factor 7 same items as the factor 1 and the items in factor 7 have lower loading factor then in factor 1 so it's decided that the factor 7 will be eliminated. Then, the new factor will be only 6 factor develop from the analysis and new name for each factor produced as the Chemistry with friends (Factor 1), Students' Engagement (Factor 2), Students' Involvement (Factor 3), Similarity with friends (Factor 4), Students' contribution (Factor 5) and Cooperate with friends (Factor 6).

Besides that, the analysis from the level of importance for overall level of friendship, there were 148 students rated the scale 5 as their level of importance and stated that their friend was very importance in their life. For the level of agreement of chemistry (F1) from the analysis, the mean score 4.31 which indicates that the most students agree that have the chemistry with their friends. Thus, the mean score of frequency level participation or involvement (F2 and F3) of students towards the activities were 3.89 and 3.98which mean that the students were often involved in the engagement and involvement the activities in university with their friends. The mean score of similarity with friends (F4) was 3.76. It shows that their often have the same similarity or interest with their friends. Lastly, the mean score of contribution and cooperation of the students were 4.29 and 4.30 which indicates that the students always give the contribution and cooperation with their friends in classroom or outside the class.

In this study, the data used was non-normal data. Because of the non-normal data, the Spearman Rho Test was used in order to see the relationship between all factors test in instruments while the chisquare to find the relationship of the genders with the chemistry and engagement of the students. From the findings, it concludes that there are no relationship between genders with chemistry and engagement. In friendship, it not necessarily involves the difference gender; the chemistry in the friendship can be created if it is from the same gender. That mean, women and men have their own pattern in friendship.

\section{Conclusion and Recommendations}

The Friendship Instruments was developed in this study in order to acquire the level of agreement on the chemistry of the students between their friends and the frequency of level of participant or involvement of the student towards the activities. The used of this instrument was to measure the level of friendship between SQS students. From the findings, the mean score level of importance is high and indicates that $64 \%$ of the students stated that the friendship is very important in students' lives. Based on the result for the gathered using this instrument, the chemistry show 4.31 for the mean score means that mostly students agree that they have their chemistry with their friend. Thus, the mean score of frequency level participation or involvement of the student towards the activities 3.89 and 3.98 which mean that the students were often involved in the engagement and involvement the activities in 
university with their friends. The mean score of similarity with friends was 3.76 and shows that they often have the same similarity or interest with their friends. Lastly, the mean score of contribution and cooperation of the students were 4.29 and 4.30 which indicates that the students always give the contribution and cooperation with their friends in classroom or outside the class. By using the chisquare, there are no relationship between genders in chemistry and engagement of SQS students.

There were several limitations in this study which have prevented more significant findings. First limitation in this study is the demographics of the respondents. From the findings, the result was more dominated by woman. If we consider finding the difference in type of friendship in genders, this issue can be limit of the study. The second limitation is the findings are inaccuracy. All respondents were assumed to answer honestly. With the fixed answers, the respondents cannot express their own opinions and give more creative answers. More items in instruments also become the limitation in this study. The respondents feel bored to read and answer the instrument. The respondents will answer the instrument without read it first and it will give the poor result.

\section{References}

Bartholomew, D., Knotts, M., \& Moustaki, I. (2011). Latent variable models and factor analysis: A unified approach. ( $3^{\text {rd }}$ ed.). West Sussex, UK: John Wiley \& Sons.

George, D., \& Mallery, P. (2003). SPSS for Windows step by step: A simple guide and reference. 11.0 update (4th ed.). Boston: Allyn \& Bacon.

Igwenagu, C. (n.d.). Fundamentals of research methodology and data collection. Retrieved from https://www.researchgate.net/publication/303381524_Fundamentals_of_research_methodology and_data_collection.

Mauk, \& Joseph, A. (1970, January 1). Friendship and Student Engagement, Achievement, and Persistence in College. Retrieved from https://diginole.lib.fsu.edu/islandora/object/fsu:180920.

Ronald (2014), How Are Men's Friendships Different From Women's?, Retrieved on 11 December 2019, from https://www.psychologytoday.com/us/blog/cutting-edge-leadership/201410/howare-men-s-friendships-different-women-s.

Schmeiser (2017), Gender Differences in Friendships Increasingly Important as Marriage Rates Drop, Retrieved on 11 December 2019, from https://observer.com/2017/03/gender-differencesfriendship-marriage-rates-drop/ 